\title{
Risk Assessment and Sustainability of Wastewater Treatment Plant Operation
}

\author{
Irena Tušer ${ }^{1}(\mathbb{D})$ and Alena Oulehlová ${ }^{2, *(\mathbb{D})}$ \\ 1 Department of Security and Law, AMBIS College, Lindnerova 1, 18000 Prague, Czech Republic; \\ irena.tuser@ambis.cz \\ 2 Department of Military Science Theory, University of Defence, Kounicova 65, 66210 Brno, Czech Republic \\ * Correspondence: alena.oulehlova@unob.cz; Tel.: +420-973-443-155
}

Citation: Tušer, I.; Oulehlová, A. Risk Assessment and Sustainability of Wastewater Treatment Plant Operation. Sustainability 2021, 13 , 5120. https://doi.org/10.3390/ su13095120

Academic Editors:

Gitana Dudzevičiūtè and Ieva Meidutè-Kavaliauskienè

Received: 4 March 2021

Accepted: 29 April 2021

Published: 3 May 2021

Publisher's Note: MDPI stays neutral with regard to jurisdictional claims in published maps and institutional affiliations.

Copyright: (c) 2021 by the authors. Licensee MDPI, Basel, Switzerland. This article is an open access article distributed under the terms and conditions of the Creative Commons Attribution (CC BY) license (https:// creativecommons.org/licenses/by/ $4.0 /)$.

\begin{abstract}
Water and water management, which also includes wastewater treatment plants (WWTPs), are considered essential elements critical infrastructure. A disruption of their operation can result in the discharge of wastewater into the environment without having been adequately treated. This can cause health problems, contamination of soil, groundwater and surface water, etc. In order to provide operational safety and sustainability of WWTP operation, it is necessary to establish protection against potential risk activation, together with risk minimization and enhanced preparedness to address the risks. The article deals with the application of risk management stages on the selected object of the municipal WWTP facility in the form of a case study. The risk identification phase consisted of the identification of assets and risks. The assets were grouped together due to the complexity of the WWTP operation. A combination of methods, a safety audit, a checklist and semi-structured interviews were used to identify the risks in three iterations. A risk register was created as a result of the risk identification phase. Subsequently, a risk analysis was carried out, in which the scenarios of the risk impact on the assets were examined, the index levels of probability and impacts were determined, and the risk estimate was performed. The Bowtie Analysis Method was used to illustrate the causes and consequences for one of the critical risks. The result of the study is the risk evaluation identified undesirable and unacceptable risks for which risk management methods were proposed
\end{abstract}

Keywords: environment; risk; risk management; risk analysis; risk assessment; sustainable development; wastewater treatment plant (WWTP)

\section{Introduction}

Municipal wastewater treatment plants (WWTPs) represent public benefit processes focused on the achievement of environmental objectives (promotion of water reuse, protection of the aquatic environment, improvement the aquatic ecosystems status [1], reduction of environmental contamination) rather than economic benefits [2]. Wastewater treatment is an essential process in society [3], therefore it was included among the Sustainable Development Goals [4]. The European Union has responded to the need to guarantee these processes by issuing regulations [5,6] aimed at reducing of surface water pollution by municipal wastewater. This requires the European Union member states to ensure that discharge of urban wastewater and its effects are monitored [7].

A financial support to build and renovate wastewater management systems was provided to the European Union member states in order to assist achievement this goal. This contributed to the fact that only $2.3 \%$ of the population in the European Union still live in households without basic sanitary facilities [8] whereas the share of the European population with access to sewerage systems averages at $65-100 \%$ [9]. The WWTP is a complex technological facility. During its operation internal sources of risks can be activated while being simultaneously affected by external risks. Project documentation, operating 
rules, operating logbook, quality certificates, etc. contribute to risk minimization and provision of operational safety [10] in the WWTP design and operation phase. Despite the implementation of safety and mitigation measures, it still represents a process, in which the reliability of the human factor, technical equipment and financial resources play their role.

For this reason, it is necessary to implement a continuous risk management process for WWTP operation.

\section{Literature Review}

Prior to the actual implementation of the risk assessment on the selected WWTP, the authors of the article have gathered information and facts from their previously implemented activities within the risk management. The scientific literature research for the risk identification phase was focused on the identification of risks related to the WWTP operation. Its implementation identified external risks of terrorism, floods, strong wind/hurricanes, earthquakes, glaze, icing, cyber security breaches, pandemics (causing the absence of key personnel) and power outages [11,12].

Some studies also focus on assessing the climate change impact in relation to the efficient performance of the WWTP $[13,14]$. The impact of climate change on the WWTP performance was assessed in the study by Abdulla through three parameters: biochemical oxygen demand (BOD); chemical oxygen demand (COD) and total suspended solids (TSS). The study concludes that the difference in the performance of WWTP in the winter period can be seen as a result of the decrease in the precipitation amount. This phenomenon may subsequently lead to a high BOD and COD load due to the reduction in the amount of the infiltrated precipitation water into the sewerage system. In the summer, on the other hand, the influencing factor caused by climate change tends to be the increase in the temperature [13].

Reuse of wastewater is becoming increasingly unavoidable as a result of the dynamic climate change due to the growing scarcity of water resources. On the contrary, greenhouse gases associated with nitrification/denitrification processes occur as an intermediate product during wastewater treatment. They are emitted into the atmosphere [14].

Other factors that affect the quality of treated water are pollutants such as personal care products $(\mathrm{PCP})$. Current research examines some of the major components commonly found in PCPs, focusing on their toxicological profile, their influence and the effect on WWTPs worldwide as well as their persistence and biodegradability [15]. Purified water can, among other things, be used for irrigation in water-scarce areas or enriching surface water bodies. For these reasons, it is important to know the types of additives in the PCP products and monitor their presence and impact on WWTP resources together with their behavior in the environment [15].

An expert study [16] deals with the continuous improvement of the infrastructure resilience, especially of wastewater treatment plants (WWTPs), which play a key role in the life cycle of cities. Changes in the hydrological response of river basins due to urban development, population growth, global warming and sea levels rising have increased the frequency and intensity of floods. The sustainability of flood activities requires a better understanding both of flood risks as well and the infrastructure functioning in the context of resilience, ways of the risks impact mitigation, rebuilding adaptive factors, etc. Karamouz et al. (2019) deal with the implementation of these measures in their article.

The above-mentioned external threats to WWTP operators are less manageable, despite this, they can be prevented by introducing both offensive and defensive measures. Internal sources of risks include obsolete WWTP infrastructure and its subsequent destruction or failure, moving machine parts (screens, rakes, conveyors and more), chemical leakage, communications and their unevenness, height differences, pollution, site lighting, tripping $[11,17,18]$. Since most of the WWTP technology is activated automatically, it is essential to have well-secured facilities where machinery and equipment are used, and the operator should pay close attention to the movement in the location around these facilities [17]. 
Recurring operational errors occurring in the WWTP facilities include the risk of non-compliance with work procedures, such as leaving tanks and pits open. In this way, the WWTP operators neglect proper handling of the heavy lids (covers) securing these entrances, which can result in falling into a pit or even drowning [19]. Another negative phenomenon is damage to electrical wires or their covers, which can result in electric shock [18]. Last but not least, a worker (professional operator) in the facility comes into direct contact with wastewater or bioaerosols [20-22] that can cause infectious diseases [23], acute toxic effects, inflammatory and allergic diseases, chronic obstructive pulmonary diseases (COPD), fetal harm and cancer [24-26]. Other examples of occupational safety procedures violation may include unprofessional handling of chemicals (flocculants, disinfectants, etc.) [27] or direct contact with compounds created in wastewater treatment processes (hydrogen sulfide, methane) without the use of body and respiratory protective equipment [28].

The WWTP operator is responsible for systematic and continuous provision of operational safety, including risk minimization under both normal and abnormal operating conditions [29]. The execution of this task can be carried out through the tools of business continuity planning and risk management, which takes into account both the internal and the external context of the organization (system), including the interaction of stakeholders. The purpose of the risk management is to create value and protect value. Its application can increase performance efficiency, support the achievement of goals and contribute to the development of innovation [30].

The presented analysis of scientific literature and studies shows that the current research focuses on individual risks related to the WWTPs operation and their treatment. The risks are not, however, addressed comprehensively, and or interconnectedness of operational, object, health and natural disaster risks arising from the WWTP operation is not considered. Based on this fact, the research described in the article aims to implement a case study of the WWTP risk management. The case study identifies technological, operational, health and environmental risks arising from the WWTP operation. A combination of risk identification methods was used to identify the risks in order to minimize the disadvantages of the individual methods used, and at the same time a complete assessment of the WWTP operation was performed, as recommended by Łój-Pilch and Zakrzewska [31] and Coze [32]. The authors of the study did not address ecological risks due to the complexity of mutual ecosystem interactions and the valuation of environmental loss. Furthermore, they did not address the quantitative microbial risk assessment due to the unavailability of data. The proposed risk minimization measures, based on the risk assessment results, shall contribute to increasing the WWTP daily operation intensity as well as to protection of the population and the environment.

The case study was carried out in a small municipality in the Slovak Republic. The WWTP operator has not yet implemented any risk management. The case study provides relevant data on the identified risks, their levels and proposes measures to minimize them.

\section{Materials and Methods}

A case study of the operated WWTP risk management was carried out for a small municipality with 2123 inhabitants in the Slovak Republic. It is a mechanical-biological treatment plant, which was designed for 1250 equivalent inhabitants. The WWTP forms a set of facilities and equipment for the sewage water treatment fed to the treatment plant from the municipality by the existing sewerage system before its discharge into the recipient.

General risk management procedure according to ISO 31000 [30] was used for the implementation of WWTP risk management which was extended by the authors' approach. The authors [33] explain how to proceed in the risk identification and risk analysis phases in more detail than ISO 31000 [30]. The use of these two general approaches enabled the authors of the article to define in more detail their implementation procedure of WWTP risk 
management. Figure 1 is based on general approaches [30,33] and extended by a specific implementation procedure of the research authors, which is further described in Section 3.

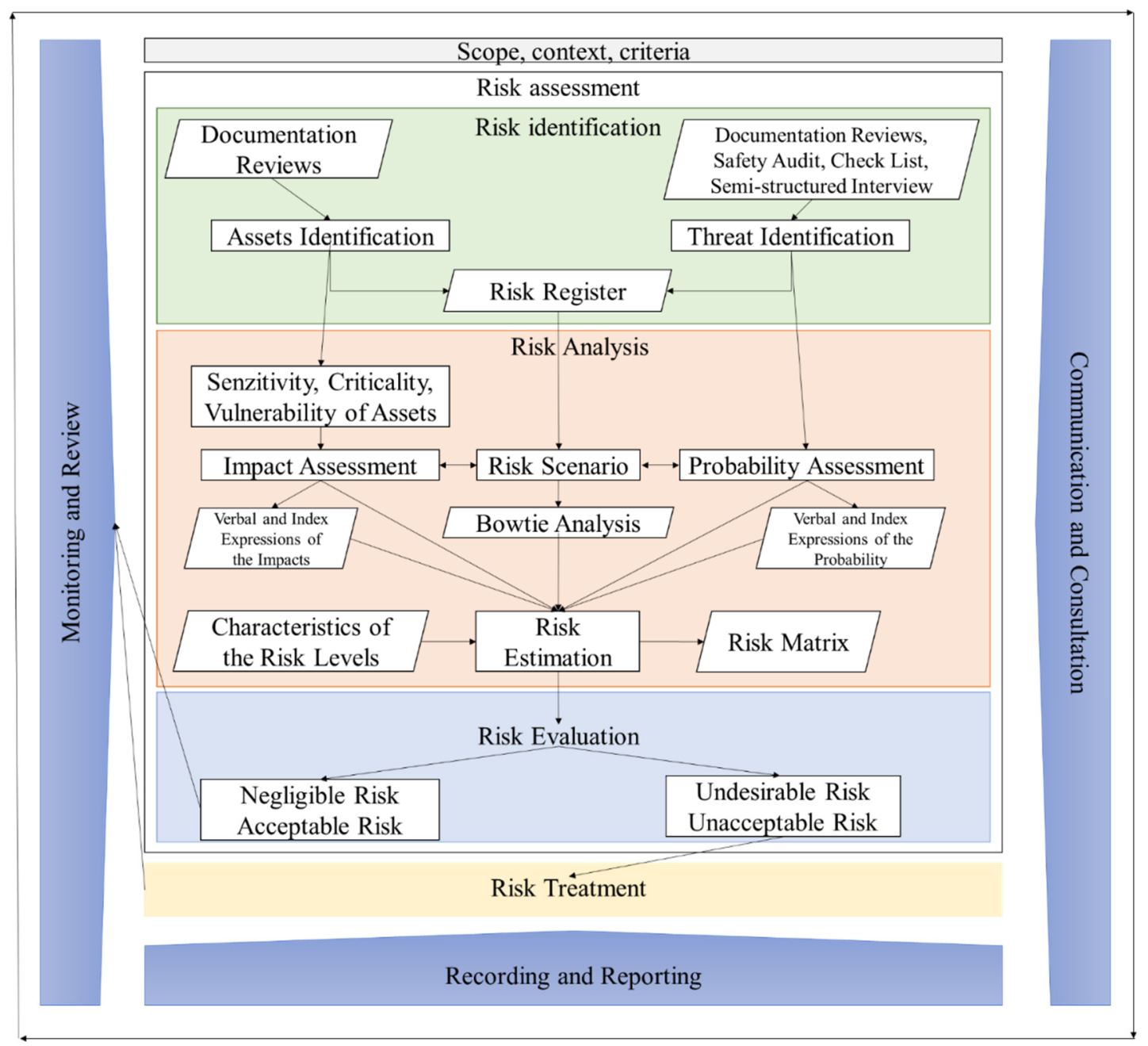

Figure 1. Approaches to the WWTP risk management. Source: adapted and complemented by authors [30,33].

The applied risk management process for the WWTP was performed using interrelated activities. The article in Section 3 deals with the presentation of the results from the scope, context, criteria, risk assessment and risk treatment phases.

The purpose of establishing the scope, the context and the criteria is to customize the risk management process, enabling effective risk assessment and appropriate risk treatment. Scope, context and criteria involve defining the scope process, and understanding the external and internal context [30]. This is important for the quality and applicability of the assessment results. If the risk assessment objective is not clear from the beginning, it is not likely that the assessment answers the questions that need to be answered [34].

Risk assessment is the overall process of risk identification, risk analysis and risk evaluation. Risk assessment should be conducted systematically, iteratively and collaboratively, drawing on the knowledge and views of stakeholders [26]. Risk identification is one of the crucial steps in the whole process. If the risk is not identified, it cannot be included in the risk analysis. Various structured or unstructured, qualitative or quantitative risk identification methods were used in this step.

The risk identification team used documentation reviews, safety audit, semi-structured interviews and a checklist to identify the risks. Documentation reviews are a method based on studying the documentation of the examined object and subsequent identification of potential risks. The technique was implemented in the following steps [35]: 
- Identifying the available source of project documentation;

- Identifying appropriate parties to review the documentation;

- Reading the documentation with an eye to risk and document;

- Cataloguing any risk issues;

- Communicating any new risk.

This technique did not require any special skills, only knowledge of the processes described in the reviewed documentation and an idea of potential risks existence in them. The outputs identified the risks, sources of risks and triggers captured during the analysis [31].

Safety audit was carried out by a small team, which, with the help of knowledge resulting from documentation reviews, interviews or checklists, identified deviations from the normal state [35-37]. Safety audit serves as a proactive [38] and systematic tool for monitoring safety and sustainability. The safety audit consisted of inspections, in which interviews with employees were used or checklists were filled in. Based on the results of the inspection, corrective measures or even re-audits were planned.

Semi-structured interviews represent the means of obtaining in-depth information and opinions from individuals. A set of questions needed to be created to use them. Semi-structured interviews are based on asking questions to respondents from a prepared set. A semi-structured interview allows more freedom for conversation when analyzing a problem [39].

A checklist is a procedure based on a systematic check of the fulfilment of predetermined conditions and measures. This means that its application assesses the state of a particular system. Depending on the complexity of the system, these can be simple or complex forms [39]. The procedure for applying this method is as follows [35]:

- Creation of a checklist and its subsequent validation;

- Checklist application-obtaining answers;

- Result evaluation.

Part of the risk identification phase is also asset identification, their vulnerability, sensitivity and criticality. The output of this phase was a created risk register $[35,36]$. The risk register expresses the relationship between the risk and its impact on the asset, which enters the risk analysis phase.

Risk analysis includes a detailed assessment of the consequences, probabilities, scenarios, uncertainties and risk management measures taken so far. Risk analysis can be undertaken with varying degrees of detail and complexity, depending on the purpose of the analysis, the availability and reliability of information, and the resources available [30]. The Bow Tie Analysis method is often used in the risk analysis phase. The technique is used to graphically display and communicate risk information in situations where an event has a number of possible causes and consequences. The Bow Tie diagram links the hazard and the consequences through a series of event lines and illustrates the "routes" to accident. The barriers that have been, or are planned to be, implemented are linked to the event lines to which they are relevant. It is a simplified representation of the Fault Tree Analysis and the Event Tree Analysis [35,39,40].

The results of the risk analysis phase are displayed in the risk matrix [30,41]. The risk matrix is a way of displaying risks according to their impact and probable possibility of occurrence. The degree of risk acceptability was also determined as part of the risk matrix creation.

Risk evaluation involves comparing the results of the risk analysis with the established risk criteria to determine where additional action is required [30].

The purpose of the risk treatment is to plan and implement measures for selected risks [30], with priority given to the most serious risks. Risk treatment that deals with negative consequences is sometimes referred to as "risk mitigation", "risk elimination", "risk prevention" or "risk reduction" [42]. Risk treatment must be carried out in accordance with the duties and objectives of the organization. When choosing risk treatment options, it is necessary to consider all the obligations, responsibilities and tasks of the organization with the relationships and views of stakeholders [43]. 
Recording and reporting is used to document the results and their changes. It is an integral part of the organization management and the entire risk management process. Monitoring and reviewing serves for continuous improvement of the risk management process quality with an emphasis on risk activation prediction. Communication and consultation serve to understand the risks by all stakeholders and to obtain feedback. These phases are not dealt with within Section 3.

\section{Results and Discussion}

Implementation of WWTP risk management was started in accordance with the defined methodological procedure in Figure 1 and its description in Section 2.

\subsection{Scope, Context, Criteria}

This step was crucial as the entire risk management process, in particular the decisionmaking process about selecting appropriate methods for risk identification and analysis, was adapted according to it to enable risk management.

Risk management was applied at the operational level, which influenced the definition of the objective and scope. The case study aimed to carry out a risk assessment for the operated WWTP and, based on the results, to propose countermeasures to increase the operational safety and minimize the impacts on population and the environment. The output was a proposal for risk management measures to deal with the risk based on the results of a semi-quantitative risk assessment.

Based on the available sources and the obtained information, the research team first performed a characterization of the WWTP operation, which was necessary for determining the boundaries and context of the assessed system. Collection of information continued in the next stages based on the requirements of the researchers. In this step, the use of appropriate risk identification methods was also considered. Risk management had not previously been carried out at the WWTP in operation, so the criteria for method selection were established as follows-they must be:

- Applicable both in the short and medium-term horizon;

- Applicable both at organizational or project level;

- Easy to use;

- Applicable for a small team of evaluators (up to about 10 people) performing risk assessment;

- Have low or medium specialist expertise level for its proper use;

- Applicable to the strategic, tactical and operational levels of a decision-making process;

- Require a low or medium initial need for information;

- Should rather use a qualitative method.

It was decided to use a combination of several risk identification methods based on the established criteria. This resulted in the use of documentation reviews, a safety audit combined with interviews and a checklist which general procedure and principles of use were described in Section 2.

The boundaries of the system were chosen in accordance with the boundaries of the WWTP operation. The internal context was determined in accordance with the task of the company operating the WWTP, i.e., to contribute to providing safety of the WWTP operation through the risk management implementation. The external context was related to safety, primarily to the population and the environment, as well as to the municipality in which the operated WWTP is located.

\subsection{Risk Assessment}

The implementation of the risk assessment was divided into 3 steps in accordance with ISO 31000 [30].

\subsubsection{Risk Identification}

This step was divided into 2 interrelated steps, the asset identification and the risk identification. 
The first step was to identify the assets. The identification of assets was based on documentation reviews.

The internal documentation that the members of the safety audit studied included:

- Standards observed;

- Results of previous inspections, audits, etc., procedures for commissioning, normal operation, shutdown and occurrences;

- Injury reports;

- Accident reports;

- Maintenance records (device inspections, tests, inspections);

- Characteristics of process materials.

A list of assets of the operated WWTP was created based on the documentation reviews, where damage or malfunction had a significant impact on the fulfilment of the WWT task. The purpose of each asset was described within the asset characterization. The characterization and description of the purpose of individual assets showed that it is possible to group some assets according to their fulfilled purpose in the WWTP. An overview of key grouped assets in the analyzed WWTP is given in Table 1.

Table 1. Identified grouped assets of the assessed WWTP.

\begin{tabular}{cl}
\hline 1 & Sewer inflow shaft \\
\hline 2 & Pumping station — rake basket, submersible sludge pumps, lifting equipment (pulley) \\
\hline 3 & Pipes and open gutters with wastewater and sludge throughout the complex \\
\hline 4 & Blowing system \\
\hline 5 & Biological reactors, activation, primary and secondary sedimentation tanks \\
\hline 6 & Automatic information and control system (software) \\
\hline 7 & Sludge management (sludge thickener tank, sludge pump, sludge dewaterer) \\
\hline 9 & Discharge facility (measuring facility, Parshall trough) \\
\hline 10 & External facilities and communications around the WWTP area \\
\hline Authors' own source.
\end{tabular}

The second step aimed to identify both the internal and external risks that affect or may affect the WWTP activities. This step represented a crucial step in the whole case study. A combination of documentation reviews, safety audit, check-list and semistructured interviews was used to identify risks. The whole process of risk identification was performed iteratively, as all the risks of the individual subsystems had not been identified at the WWTP site during the first investigation. One iteration was performed in collaboration with an external expert. A total of 3 iterations, in which all risk identification methods were applied simultaneously, were performed. This approach provided the implementation of a comprehensive risk identification for the WWTP operation.

A photo documentation of individual elements of technology/assets was performed as part of the first safety audit, the researchers performed a characterization of their vulnerability, criticality and resilience, and described the measures implemented so far to reduce the risk impacts.

In subsequent iterations, conditions and operational activities, that could lead to deviations from the normal state, non-compliance with normative legal acts, injuries and accidents were identified, subsequently risks were identified and the impacts of their operation were described. Pre-prepared semi-structured interviews and a checklist were used in these iterations. Members of the safety audit asked the WWTP employees questions from a pre-prepared list. The semi-structured interview was chosen because it allowed additional questions to be asked based on the employees' answers. The questions were created open and each question covered one issue. Thanks to this method, thorough information about the operation and activities carried out at the analyzed WWTP was 
obtained from the WWTP employees. The checklist was created as a simple checklist based on the WWTP operational documentation, retrospective data and normative legal acts governing the WWTP operation. The checklist was subsequently evaluated on the basis of the yes/no answers. Each answer to the question was equivalent. Part of the checklist is given in Appendix A. The results of the semi-structured interviews and the checklist were compared with the findings of the safety audit members and were used for the purposes of the risk register creation.

The researchers identified 58 risks, a significant part of which were related to technological risk, health risks, natural risks and human failure. Examples of identified risks:

- Outflow of sewage and sludge;

- Reduction in sludge pump performance;

- Reduction in cleaning efficiency;

- Electric shock;

- Spread of infectious diseases;

- Fall;

- Slipping;

- Non-functional software;

- Heavy rainfall.

Based on the results of the retrospective data, safety audit, semi-structured interviews and scientific literature research, a register of risks was created for the researched WWTP. The risk register provided a comprehensive overview of whether the risk affects the asset. Table 2 shows an example of a risk register where the cross indicates the relationship between the risk and the asset. The asset numbers in Table 2 correspond to the asset numbers listed in Table 1. All identified links were subsequently included in the risk analysis and risk evaluation.

Table 2. Example of created risk register for the selected WWTP.

\begin{tabular}{|c|c|c|c|c|c|c|c|c|c|c|}
\hline \multirow{2}{*}{ Risk } & \multicolumn{10}{|c|}{ Assets } \\
\hline & 1 & 2 & 3 & 4 & 5 & 6 & 7 & 8 & 9 & 10 \\
\hline Fall & $\mathrm{x}$ & $\mathrm{x}$ & $x$ & $x$ & $\mathrm{x}$ & $x$ & & $\mathrm{x}$ & & \\
\hline Intoxication & & $x$ & & & & & $x$ & & & \\
\hline Hearing damage & & & & $x$ & & & $x$ & & & \\
\hline Electric shock & & $x$ & & $x$ & $\mathrm{x}$ & & $\mathrm{x}$ & & & \\
\hline Clogging of the rake basket & & $x$ & & & & & & & & \\
\hline
\end{tabular}

The researchers determined parameters for each identified risk, danger level and motivation and approach in order to subsequently determine the description of the probability of risk activation.

\subsubsection{Risk Analysis}

The purpose of risk analysis was to understand and describe the causes of risk activation, including the determination of their activation levels for each analyzed asset. Impacts were described for individual assets and they were assigned to the levels. The scenarios acting on each risk were assessed. On this basis, the probability of risk activation was determined for each risk acting on the asset. In this step, semi-quantitative impact and probability description scales developed for the study were used. Existing measures and their functionality were taken into account when determining the individual levels of probabilities and impacts.

The determination of risk activation levels was based on retrospective data on the occurrence of risks in the previous period, if there were records in the internal documentation, and on the experience of the researchers. Therefore, the subjective verbal probability 
of risk activation was determined. The set verbal and index expressions of risk activation are given in Table 3.

Table 3. Verbal and index expressions of the risk activation probability.

\begin{tabular}{ccl}
$\begin{array}{c}\text { Verbal } \\
\begin{array}{c}\text { Expression of } \\
\text { Probability }\end{array}\end{array}$ & $\begin{array}{c}\text { Index } \\
\text { Expression of } \\
\text { Probability }\end{array}$ & \multicolumn{1}{c}{ Description of Probability } \\
\hline Negligible & 1 & $\begin{array}{l}\text { The occurrence of the phenomenon is almost ruled out, } \\
\text { almost zero. }\end{array}$ \\
\hline Low & 2 & $\begin{array}{l}\text { The occurrence of the phenomenon is unlikely } \\
\text { but possible. }\end{array}$ \\
\hline Medium & 3 & The phenomenon will certainly occur in a given time. \\
\hline High & 4 & The phenomenon occurs quite often in a given time. \\
\hline Very high & 5 & $\begin{array}{l}\text { The phenomenon occurs very often, respectively it } \\
\text { is continuous. }\end{array}$ \\
\hline
\end{tabular}

Authors' own source.

Research took into account the results of the sensitivity, criticality and vulnerability analyses of individual assets to describe the impacts. Since it is a complex technology, its individual elements have different prices and are all necessary for quality wastewater treatment, the description of the impacts was approached verbally. Another reason why a verbal description was used was the complexity of the issue of financial quantification of environmental loss. Solely in the case of human health impact assessment, the duration of treatment was taken into account. Table 4 provides a verbal and index expressions of the impacts.

Table 4. Verbal and index expressions of the impacts.

\begin{tabular}{|c|c|c|}
\hline $\begin{array}{l}\text { Verbal } \\
\text { Expression } \\
\text { of Impact }\end{array}$ & $\begin{array}{l}\text { Index } \\
\text { Expression } \\
\text { of Impact }\end{array}$ & Qualitative Description of Impact \\
\hline Marginal & 1 & $\begin{array}{l}\text { Impacts are almost insignificant for the analyzed facility, minor injuries of employees do not } \\
\text { require medical treatment or home treatment, no wastewater treatment is necessary, the quality } \\
\text { of discharged water is without changes, slight damage to the treatment plant building, water } \\
\text { supply is not significantly limited. }\end{array}$ \\
\hline Boundary & 2 & $\begin{array}{l}\text { The impacts are insignificant for the analyzed facility, injuries to employees require a treatment } \\
\text { period of 1-10 days on sick leave, the quality of discharged water is without changes. }\end{array}$ \\
\hline Serious & 3 & $\begin{array}{l}\text { The impacts are serious for the analyzed facility, injuries to employees require treatment for more } \\
\text { than } 10 \text { days on sick leave, the impacts affect the treatment technology, the quality of discharged } \\
\text { water is at the edge of the permitted limits. }\end{array}$ \\
\hline Extensive & 4 & $\begin{array}{l}\text { The impacts are quite extensive for the analyzed facility, injuries to employees have permanent } \\
\text { consequences, treatment technology is interrupted, the quality of discharged water exceeds the } \\
\text { permitted limits, necessary interruption of activities and renewal of WWTP technological parts, } \\
\text { impacts affect both the residents and the environment. }\end{array}$ \\
\hline Catastrophic & 5 & $\begin{array}{l}\text { The impacts are catastrophic for the analyzed facility, it is not possible to resume operation, death } \\
\text { of employees, wastewater is discharged directly into the recipient, serious risk to the } \\
\text { environment and the health of the residents in the vicinity of the recipient. }\end{array}$ \\
\hline
\end{tabular}

Authors' own source.

The created risk register was used in the risk analysis phase to create scenarios on the basis of which the probability of activation of each risk and the extent of impacts for the relevant asset were determined. Each risk was assigned an index value from Table 3 and the impact on assets were assigned an index value from Table 4 . 
The risk analysis used the Bowtie Analysis method, which was used to display and communicate information about the risk, where the occurrence had a number of possible causes and impacts. At the same time, its graphical representation showed suitable preventive and reactive elements that can contribute to the reduction of the currently unacceptable risk of spreading an infectious disease. An example of a Bowtie Analysis [26] for the risk of spreading an infectious disease in the employee(s) is shown in Figure 2. The example for this risk was chosen because the safety audit revealed non-compliance with occupational health and safety (especially unuse of personal protective equipment) and not following safety procedures, i.e., insufficient functionality of preventive risk management elements. Their application would significantly reduce the risk and increase the human health protection.

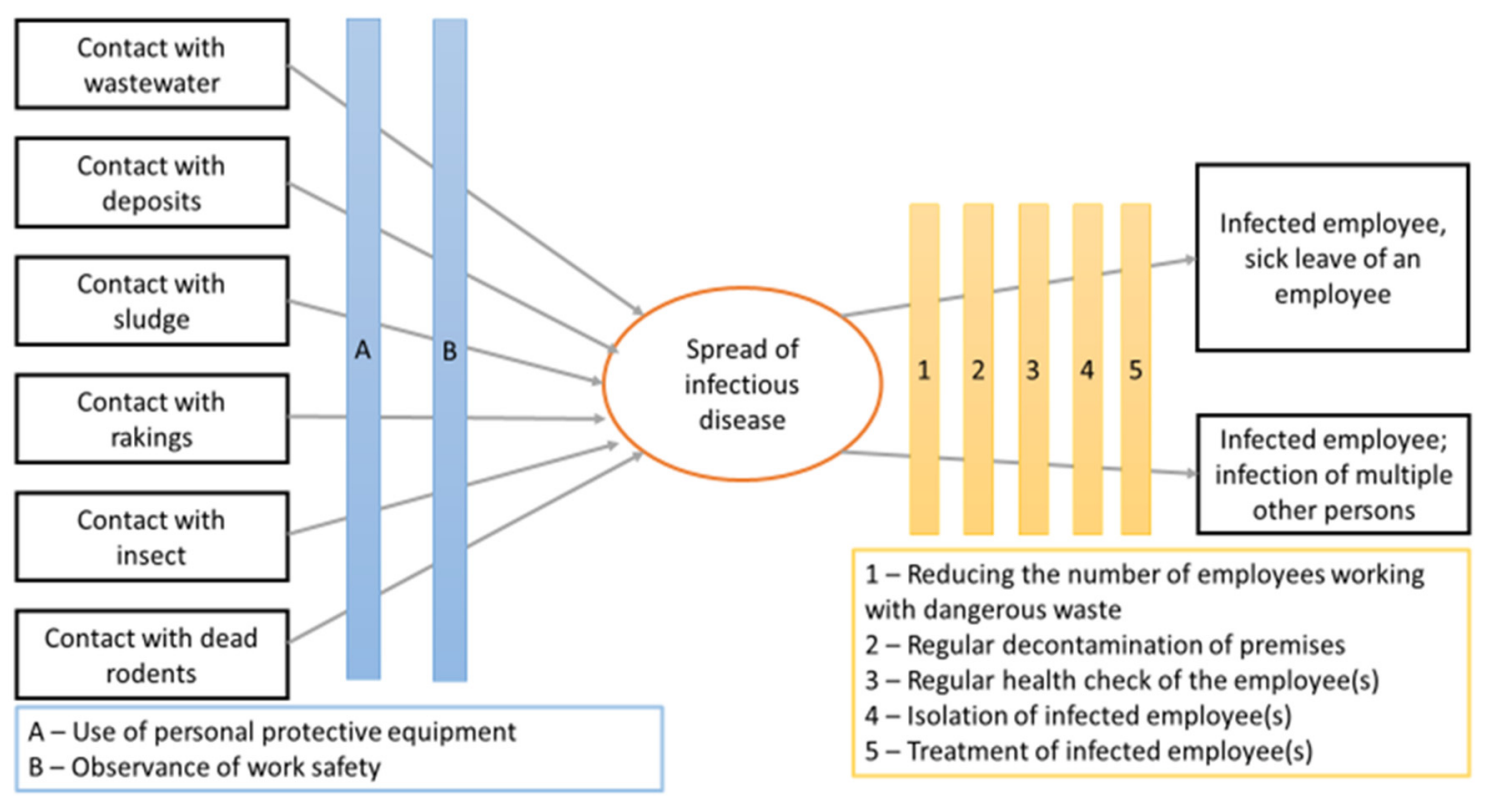

Figure 2. Bowtie Analysis for the risk of spreading an infectious disease among the employee(s). Authors' own source.

Risk estimation was performed based on a combination of probability and impact. Based on the indices specified in Tables 3 and 4, the risk could take values in the interval $\langle 1 ; 25\rangle$. The research team set four levels of risk. Each level was assigned a characteristic in relation to the subsequent risk treatment or risk monitoring. The characteristics of the individual risk levels are given in Table 5. The results of the risk estimation were subsequently entered into the risk matrix. They can be seen in Table 6. The R designation indicates the risk and the number indicates the serial number of the estimated risk.

\subsubsection{Risk Evaluation}

At this stage, the results of the risk analysis were compared with the set risk levels, in particular with the reference level, which was set at value 9. The value of the reference level was set based on an estimate of the research team with regard to the objective and scope of the risk assessment set out in point 3.1. The risk estimate resulted in finding that 5 risks are negligible and 17 risks are acceptable. In accordance with the established characteristics of the risk levels given in Table 5, the operator was recommended only to monitor the risks and to maintain the already existing countermeasures. Most of the estimated risks were above the established acceptance limit. For 25 undesirable and 11 unacceptable risks, the operator was suggested to consider risk treatment options. All these risks must be moved to the risk treatment phase. 
Table 5. Characteristics of the risk levels.

\begin{tabular}{ccl}
\hline Interval & \multicolumn{1}{c}{ Risk } & \multicolumn{1}{c}{ Risk Level Description } \\
\hline$\langle 1 ; 3\rangle$ & Negligible & $\begin{array}{l}\text { The risk is negligible for the subject, there is no need to implement } \\
\text { countermeasures, only to monitor the risk. }\end{array}$ \\
\hline$\langle 4 ; 8\rangle$ & Acceptable & $\begin{array}{l}\text { The risk is acceptable for the subject, countermeasures can be } \\
\text { implemented following the decision of the company management, it is } \\
\text { important to monitor the risk. }\end{array}$ \\
\hline$\langle 9 ; 12\rangle$ & Undesirable & $\begin{array}{l}\text { The risk is undesirable for the subject, there is the need to implement } \\
\text { countermeasures. }\end{array}$ \\
\hline$\langle 15 ; 25\rangle$ & Unacceptable & $\begin{array}{l}\text { The risk is unacceptable for the subject, immediate implementation of } \\
\text { countermeasures, or considering the termination of the } \\
\text { subject's activities }\end{array}$ \\
\hline Authors' own
\end{tabular}

Authors' own source.

Table 6. Risk matrix for WWTP operation.

\begin{tabular}{|c|c|c|c|c|c|}
\hline \multirow[b]{2}{*}{ Probability } & \multicolumn{5}{|c|}{ Impacts } \\
\hline & $\begin{array}{c}1 \\
\text { Marginal }\end{array}$ & $\begin{array}{c}2 \\
\text { Boundary }\end{array}$ & $\begin{array}{c}3 \\
\text { Serious }\end{array}$ & $\begin{array}{c}4 \\
\text { Extensive }\end{array}$ & $\begin{array}{c}5 \\
\text { Catastrophic }\end{array}$ \\
\hline 1 Negligible & & $\mathrm{R} 23$ & R35 & R6 & R24, R45 \\
\hline 2 Low & $\begin{array}{l}\text { R25, R46, } \\
\quad \text { R54 }\end{array}$ & $\begin{array}{c}\text { R4, R15, R17, } \\
\text { R26, R32, } \\
\text { R49, R50 }\end{array}$ & $\begin{array}{c}\text { R5, R8, R13, R 39, } \\
\text { R42 }\end{array}$ & $\mathrm{R} 57$ & $\mathrm{R} 22, \mathrm{R} 34$ \\
\hline 3 Medium & & $\mathrm{R} 2, \mathrm{R} 20$ & $\begin{array}{c}\text { R1, R3, R7, R11, } \\
\text { R14, R16, R19, R21, } \\
\text { R27, R47, R52, R53 }\end{array}$ & $\begin{array}{c}\text { R18, R28, R } \\
\text { 30, R38, R40, } \\
\text { R56 }\end{array}$ & R33, R55 \\
\hline 4 High & & & R31, R41, R44, R48 & $\begin{array}{c}\text { R10, R29, } \\
\text { R36, R43, R58 }\end{array}$ & R9, R12 \\
\hline 5 Very high & & & R51 & R37 & \\
\hline
\end{tabular}

Authors' own source.

Figure 3 shows the distribution of the occurrence of individual undesirable and unacceptable risks for individual assets. The asset numbers correspond to the asset numbers in Table 1. The most undesirable and unacceptable risks affect the assets in the biological reactors, activation, primary settling and final settling tanks. These assets are crucial for the efficient biological wastewater treatment. Three unacceptable risks affect the pumping stations-the rake basket, the submersible sludge pumps, the lifting equipment (pulley) and two unacceptable risks are associated with the effect on the asset of the WWTP operator.

\subsection{Risk Treatment}

Risk treatment was designed with regard to the internal and external context, with an emphasis on age, condition, safety, capacity and compliance with the growing requirements of normative legal acts for the operation of WWTPs. In total, 58 safety recommendations for risk treatment were proposed to the operator without their more detailed analysis of feasibility, as the company management must first confirm the risk assessment results. Subsequently, it can select and implement risk management options. Priority must be given in reducing 11 unacceptable risks. The key proposed safety measures to minimize unacceptable risks in WWTPs are listed in Table 7. Their proposal is also based on the identified situation within the safety audit. The process of planning and implementation of risk treatment falls fully within the competence of the WWTP operator. 


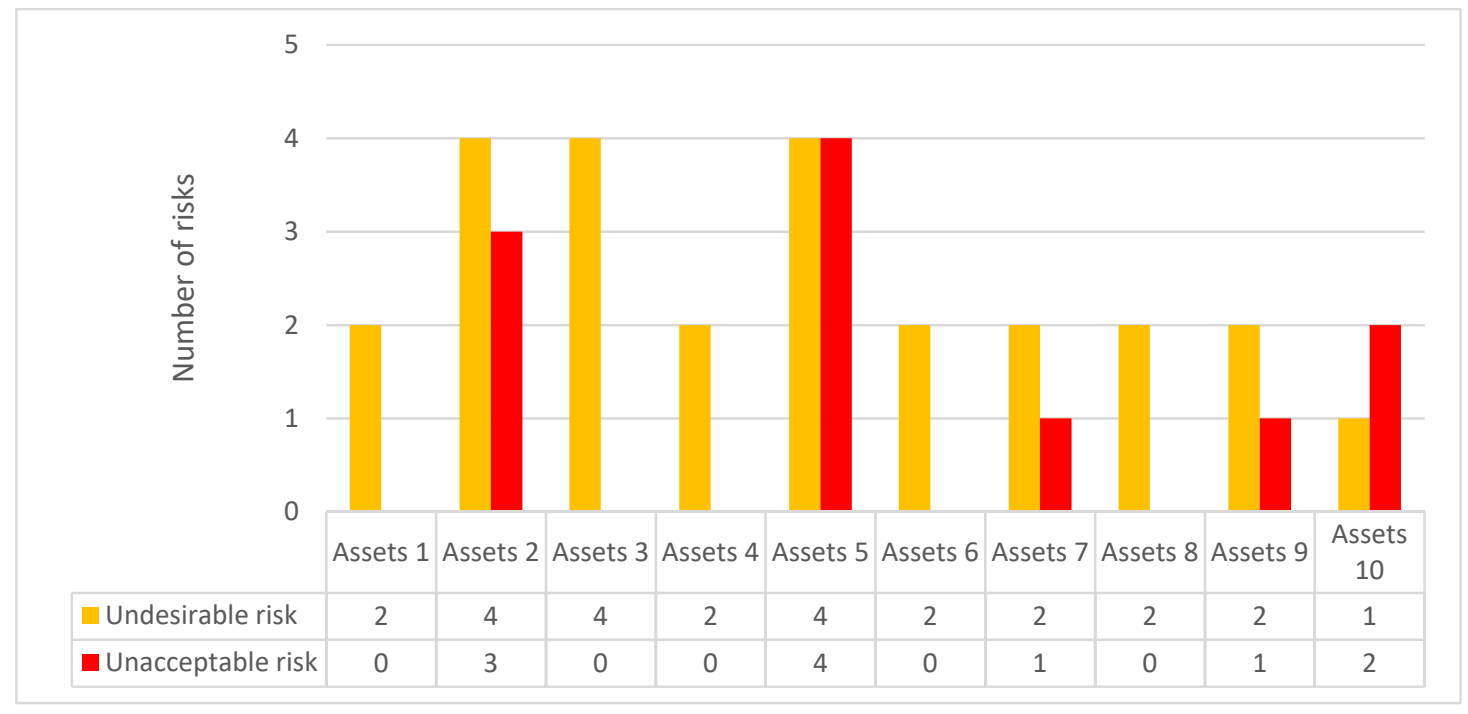

Figure 3. Number of undesirable and unacceptable risks affecting individual assets. Authors' own source.

Table 7. Proposal of security measures to minimize unacceptable risks.

\begin{tabular}{|c|c|c|}
\hline Risk Designation & Verbal Description of the Risk & Proposed Safety Measure \\
\hline R9 & Reducing the cleaning efficiency & $\begin{array}{l}\text { Installation of new control equipment for pumps and lifting } \\
\text { equipment, pulleys. }\end{array}$ \\
\hline R10 & Spread of infectious disease & $\begin{array}{l}\text { Consistent personal hygiene, use of prescribed personal } \\
\text { protective equipment (PPE), eliminate people with } \\
\text { a predisposition. }\end{array}$ \\
\hline $\mathrm{R} 12$ & Electric shock & Regular inspection, revision. \\
\hline R29 & $\begin{array}{l}\text { Rise of settled sludge and its subsequent } \\
\text { outflow over the overflow trough }\end{array}$ & Regular inspection and installation of the back-up pump. \\
\hline R33 & Electric shock & Regular inspection, revision and use of PPE. \\
\hline R36 & Fall, slipping & $\begin{array}{l}\text { Marking of dangerous places, keeping cleanliness, } \\
\text { non-slip shoes. }\end{array}$ \\
\hline R37 & Falling from the ladder & $\begin{array}{l}\text { Removal of the temporary access platform, compliance with the } \\
\text { original technology according to the project. }\end{array}$ \\
\hline $\mathrm{R} 43$ & Electric shock & $\begin{array}{l}\text { Adjustment of insulation for ceiling lighting, prevention of } \\
\text { water leakage, regular inspection, revision. }\end{array}$ \\
\hline R51 & Soil pollution & Installation of fixed piping. \\
\hline R55 & Errors due to insufficient knowledge & $\begin{array}{l}\text { Regularly recurring training in technological procedures, } \\
\text { occupational health and safety, fire protection, use of PPE. }\end{array}$ \\
\hline R58 & Inattention & Strict adherence to technological and security discipline. \\
\hline
\end{tabular}

Authors' own source.

\subsection{Discussion}

A total of 58 risks were identified for WWTP providing services to 2123 inhabitants in the implemented case study. The research $[14,27,40]$ of WWTP, to which 62,000 inhabitants are connected, identified 32 risks. It follows that the research carried out for a smaller number of inhabitants and less technologically equipped WWTP identified more risks and in more detail. A larger number of identified risks may be related to the age of the operated WWTP, the technology used, the set safety system and other variables.

Similar external threats to those reported by $[11,13,14]$ have been identified. Impacts on wastewater infrastructure can be categorized either as impacts indirectly linked to climate change or as impacts directly linked to climate change [14]. A study from northern 
Jordan [13] discusses the topic of climate change, which has a major impact on the operation of WWTPs and the quality of discharged treated water. A mere temperature raise increases biological degradation. One of the main recommendations is that urban water mains and wastewater treatment systems should be adapted and modernized to meet the corresponding anticipated challenges of weather extremes (floods and droughts) as well as the sea-level rise [13].

Reducing the impacts of climate change on the WWTP processes can also be achieved through the use of risk assessment tools such as impact assessments, continuous and systematic monitoring of WWTPs and the use of the vulnerability aspect [14]. This presented paper, in accordance with the presented opinion, also describes the application of risk management stages on the selected wastewater treatment plant facility in the municipality.

Other, currently common negative phenomena (external threats) in wastewater treatment plants include pollutants that represent a threat to wastewater treatment and regeneration (e.g., the occurrence of PCP) [15]. It is therefore important to expand and update the research on the behavior of PCP in the environment and the methods of efficient decomposition of these substances already during the WWTP process. Moreover, more environmentally friendly PCP additives must be chosen so that water reuse becomes a vital alternative that does not endanger public health and the quality of the environment [15].

Intention to improve the resilience of wastewater treatment infrastructure was also discussed in an expert study carried out for the city of New York [16]. Using multicriteria decision-making (MCDM) and implementing adaptive risk mitigation practices, such as the best management practices (BMPs), improvements to WWTP resilience were compared. The most efficient alternative solution was subsequently chosen with regard to the allocation of financial resources to individual WWTPs [16].

Technological risks depend on the technology used in the WWTP, its utilization, age, failure rate, and regularity of maintenance, etc. However, common elements can also be identified in them (breakdowns, failures, damage or overload of individual technological elements). Technological risks can be significantly reduced by proper design (application of best available techniques) and compliance with the WWTP operating conditions [44].

Consideration of potential risk, already at the design stage of a management project, allows for an effective balance between the costs of measures and risks. In some countries (e.g., Poland, Slovakia) the modernization of already existing obsolete facilities is currently more frequent than the construction of the new ones. Properly implemented modernization should be based on risk analysis [31].

Due to the characteristics of the analyzed wastewater treatment plant and the specificity of the processes used, it was and is necessary to approach different areas individually. The authors of the presented case study of a WWTP in the municipality in Slovakia have identified the health risk of spreading an infectious disease as an unacceptable risk.

The risk is activated mainly by non-compliance with work procedures and failure to use personal protective equipment, although normative legal standards require their use and the employer must provide employees with them. Failure to comply with these measures results from negligence due to human error. Other possibilities for reducing health risks deal already with the WWTP design phase of the construction or reconstruction by including safety elements protecting employees, choosing proper technology or automating production.

From the point of view of the risk analysis phase, it is important to compare the approach to risk estimation, in particular its probability/frequency and impact variables. The work [31] used a period of 3 years and a three-level scale to determine the frequency of individual risk occurrence. The presented case study, on the other hand, worked with a probability that relates to the entire lifetime of the WWTP operation and a five-level scale. Using frequency, the results of the risk assessment can be burdened by greater error and uncertainty since they work with a shorter period of risk activation. The case study provided a significantly more detailed description of the individual impact levels than [31], 
while also trying to include quantitative elements of the impact description. This helps to refine the results of the risk assessment.

The results of the case study in the risk treatment phase revealed a significant proportion of unacceptable and undesirable risks. The reason is the low level of safety measures and the age of the WWTP technology. The results served the WWTP owner as a basis for decisions to increase the WWTP capacity and quality of technology. The case study contributed to raise the safety and sustainability of the WWTP operation in the municipality and its surroundings.

Further steps of the research in the field of WWTP risk management should lead towards the quantitative definition of probability levels and impacts, monitoring and measurement of risk factors and their individual evaluation using special methods.

\section{Conclusions}

The wastewater treatment plant is an important element of the water management infrastructure of each city, which provides one of the strategic services and makes a significant contribution to provide environmental safety and sustainable development. Short-term or long-term disruption of functionality of the WWTP has extensive impacts on the population and the environment. Therefore, similar to other human activities, it is necessary to assess and manage the risks associated with the operation of the WWTP.

The risk assessment case study was carried out for a WWTP, which is intended for 1250 equivalent inhabitants. So far, none of the phases of risk management has been carried out for this WWTP, therefore the research team decided to use qualitative methods of risk identification (documentation reviews, safety audit, semi-structured interviews and a check-list). The methods were used in interrelationship and in three iterations to achieve a comprehensive risk identification. In the risk identification phase, 58 risks and 10 grouped assets were estimated and a risk register was created to examine the relationship between the risk and the assets. Subsequently, a risk analysis was performed. The output of the risk analysis was a description of the vulnerabilities of individual assets, determination of a verbal and index description of impacts and probability of risk activation and a risk estimate. Four levels of risk, where the reference level of risk was set at nine, were created as part of the risk estimate.

The results of the risk assessment show that undesirable and unacceptable risks predominate in the operated WWTP. It is necessary to immediately implement countermeasures for at least 11 unacceptable risks. The article presents possible proposals for safety measures for unacceptable risks. This situation was also confirmed by the result of the safety audit, which found out that both the technological equipment and technical condition of the operated WWTP is at a very low level and in some areas does not correspond to current best available techniques in the field of wastewater management. The overall reconstruction of the WWTP, including an increase in its capacity, would contribute to the comprehensive minimization of undesirable and unacceptable risks. The complete processed risk assessment results were provided to the WWTP operator for further use.

The article presented a proposal for the risk management screening procedure, including verification of methods suitable for the identification of risks for the WWTP for which risk management has not yet been implemented. Presented procedure and outputs (created risk register, verbal and index probability expression of danger activation, scale for verbal and index expression of impact and characteristics of risk levels) can be applied or modified for other analogous operations for safety and sustainability needs or on their basis create a uniform risk management methodology for the WWTP operation. The results for individual operations are further mutually comparable using a uniform risk management procedure. Should the risk management application be spread to WWTP operation, safety and sustainable development would be supported.

Author Contributions: Both authors work at the paper equally. Both authors have read and agreed to the published version of the manuscript. 
Funding: This research received no external funding.

Institutional Review Board Statement: Not applicable.

Informed Consent Statement: Not applicable.

Data Availability Statement: The data presented in this study are available on request from the corresponding author.

Acknowledgments: Irena Tušer would like to thank AMBIS College, Prague for its support.

Conflicts of Interest: The authors declare no conflict of interest.

Appendix A. Sample Part of a Checklist

Checklist-Inspection Certificate of the WWTP Biogas Management

\section{Findings}

A. Evaluation of changes in the state of the biogas plant (gas management) since the last comprehensive inspection; whether any installation was shut down for more than 6 months and whether the gas management did not show any defects or other deficiencies in operation.
$\square$ In order
Defects identified

B. Evaluation of whether no changes have been made that would reduce the safety and operational reliability of the equipment or its parts.
$\square$ In order
$\square$ Defects identified

C. Evaluation of the completeness and timeliness of the operational documentation of the biogas plant (gas management), especially the inspection book of gas facilities, the operating rules of the biogas plant (gas management) and in the case of the WWTP gas management, also the operating rules of the treatment plant.
$\square$ In order
$\square$ Defects identified

E. Evaluation of the function of safety, checking, measuring and control devices, including testing of simulated fault states of the entire set of sludge and gas management (biogas stations)
$\square$ In order
$\square$ Defects identified

F. Ventilation and extraction functions
$\square$ In order
$\square$ Defects identified

G. Tightness of building structures between explosion hazardous areas and explosion non-hazardous areas
$\square$ In order
$\square$ Defects identified

J. Evaluation of whether the persons performing the operation and possibly other activity at the gas installation, meet the prescribed professional competence

J1.1 Training in legal and other regulations to ensure health and safety?

J1.2 Training in fire protection?

J1.3 Training in gas equipment operating?

$\begin{array}{ll}\square \text { Yes } & \square \text { No } \\ \square \text { Yes } & \square \text { No } \\ \square \text { Yes } & \square \text { No } \\ \square \text { Yes } & \square \text { No } \\ \square \text { Yes } & \square \text { No } \\ \square \text { Yes } & \square \text { No }\end{array}$

$\begin{array}{lll}\text { J1.5 Training of persons instructed to operate electrical equipment? } & \square \text { Yes } & \square \text { No } \\ \text { J1.6 Training in first aid? } & \square \text { Yes } & \square \text { No }\end{array}$

\section{References}

1. Flores-Alsina, X.; Gallego, A.; Feijoo, G.; Rodriguez-Roda, I.; Meneses, M. Multiple-objective evaluation of wastewater treatment plant control alternatives: Simple Control Schemes with a Holistic Perspective. J. Environ. Manag. 2010, 91, 1193-1201. [CrossRef]

2. Revollar, S.; Vilanova, R.; Vega, P.; Francisco, M.; Meneses, M. Wastewater Treatment Plant Operation: Simple Control Schemes with a Holistic Perspective. Sustainability 2020, 12, 768. [CrossRef]

3. San Juan, J.L.; Caligan, C.J.; Garcia, M.M.; Mitra, J.; Mayol, A.P.; Sy, C.; Ubando, A.; Culaba, A. Multi-Objective Optimization of an Integrated Algal and Sludge-Based Bioenergy Park and Wastewater Treatment System. Sustainability 2020, 12, 7793. [CrossRef]

4. United Nations. Sustainable Development, 17 Goals. Available online: https://www.un.org/sustainabledevelopment/ sustainable-development-goals/ (accessed on 20 November 2020).

5. Directive 91/271/EEC—Urban Wastewater Treatment. Available online: https://eur-lex.europa.eu/legal-content/EN/TXT/ HTML/?uri=LEGISSUM:128008\&from=CS (accessed on 10 March 2021).

6. Directive 2000/60/EC, 23 October 2000. Establishing a Framework for Community Actions in the Field of Water Policy. Available online: http:/ / ec.europa.eu/environment/water/water-framework/index_en.html (accessed on 10 March 2021).

7. la Farré, M.; García, M.-J.; Tirapu, L.; Ginebreda, A.; Barceló, D. Wastewater toxicity screening of non-ionic surfactants by Toxalert®and Microtox®bioluminescence inhibition assays. Anal. Chim. Acta 2001, 427, 181-189. [CrossRef]

8. European Commission-Eurostat. Available online: https://ec.europa.eu/eurostat/web/sdi/clean-water-and-sanitation (accessed on 28 October 2020). 
9. Eurostat. Population Connected to at Least Secondary Waste Water Treatment. Available online: https://ec.europa.eu/eurostat/ databrowser/view/sdg_06_20/default/map?lang=en (accessed on 28 October 2020).

10. Methodological Instruction of the Department of Water Protection of the Ministry of the Environment on the Discharge of Wastewater into Groundwater, MP416. 2011. Available online: https://www.mzp.cz/C1257458002F0DC7/cz/vypusteni_ odpadnich_vod_pokyn/\$FILE/OOV-MP416_20111201.pdf (accessed on 28 October 2020).

11. Friedemann, A. Risks to America's Drinking and Sewage Treatment Infrastructure. 2018. Available online: http:/ / energyskeptic. com/2018/risks-to-americas-drinking-and-sewage-treatment-infrastructure/ (accessed on 28 October 2020).

12. Oulehlová, A. Identification of the Electricity Blackout Impacts on the Environmental Security. In Risk, Reliability and Safety Innovating Theory and Practice; Taylor \& Francis Group: London, UK, 2017; pp. 2175-2182. ISBN 978-1-138-02997-2.

13. Abdulla, F.; Farahat, S. Impact of Climate Change on the Performance of Wastewater Treatment Plant: Case study Central Irbid WWTP (Jordan). Procedia Manuf. 2020, 44, 205-212. [CrossRef]

14. Zouboulis, A.; Tolkou, A. Effect of Climate Change in Wastewater Treatment Plants: Reviewing the Problems and Solutions. In Managing Water Resources under Climate Uncertainty; Springer Water, Shrestha, S., Anal, A., Salam, P., van der Valk, M., Eds.; Springer: Cham, Switzerland, 2015. [CrossRef]

15. Emmanouil, C.; Bekyrou, M.; Psomopoulos, C.; Kungolos, A. An Insight into Ingredients of Toxicological Interest in Personal Care Products and A Small-Scale Sampling Survey of the Greek Market: Delineating a Potential Contamination Source for Water Resources. Water 2019, 11, 2501. [CrossRef]

16. Karamouz, M.; Taheri, M.; Khalili, P.; Chen, X. Building Infrastructure Resilience in Coastal Flood Risk Management. J. Water Resour. Plan. Manag. 2019, 145. Available online: https://ascelibrary.org/doi/pdf/10.1061/\%28ASCE\%29WR.1943-5452.0001043 (accessed on 25 April 2021). [CrossRef]

17. Falakh, F.; Setiani, O. Risk Identification and Risk Assessment in Water Treatment Plant considering Environmental Health and Safety Practice. Energy Environ. Inf. Syst. 2018, 31, 06011. [CrossRef]

18. Łój-Pilch, M.; Zakrzewska, A.; Zielewicz, E. Impact of human factors on risks in sewage treatment plants. In Safety and ReliabilitySafe Societies in a Changing World, Proceedings of ESREL 2018, Trondheim, Norway, 17-21 June 2018; CRC Press: London, UK, 2018. [CrossRef]

19. Hauser, A.; Sathrugnan, K.; Roedler, F. Managing risks in advanced wastewater treatment plants. Water Pract. Technol. 2015, 10, 305-311. [CrossRef]

20. Verani, M.; Federigi, I.; Donzelli, G.; Cioni, L.; Carducci, A. Human adenoviruses as waterborne index pathogens and their use for Quantitative Microbial Risk Assessment. Sci. Total Environ. 2019, 651, 1469-1475. [CrossRef]

21. Carducci, A.; Donzelli, G.; Cioni, L.; Federigi, I.; Lombardi, R.; Verani, M. Quantitative Microbial Risk Assessment for Workers Exposed to Bioaerosol in Wastewater Treatment Plants Aimed at the Choice and Setup of Safety Measures. Int. J. Environ. Res. Public Health 2018, 15, 1490. [CrossRef] [PubMed]

22. Carducci, A.; Donzelli, G.; Cioni, L.; Verani, M. Quantitative Microbial Risk Assessment in Occupational Settings Applied to the Airborne Human Adenovirus Infection. Int. J. Environ. Res. Public Health 2016, 13, 733. [CrossRef] [PubMed]

23. Mao, K.; Zhang, K.; Du, W.; Ali, W.; Feng, X.; Zhang, H. The potential of wastewater-based epidemiology as surveillance and early warning of infectious disease outbreaks. Curr. Opin. Environ. Sci. Health 2020, 17, 1-7. [CrossRef]

24. Douwes, J.; Thorne, P.; Pearce, N.; Heederik, D. Bioaerosol Health Effects and Exposure Assessment: Progress and Prospects. Ann. Occup. Hyg. 2003, 47, 187-200. [CrossRef]

25. Collivignarelli, M.; Abbà, A.; Alloisio, G.; Gozio, E.; Benigna, I. Disinfection in Wastewater Treatment Plants: Evaluation of Effectiveness and Acute Toxicity Effects. Sustainability 2017, 9, 1704. [CrossRef]

26. Corrao, C.R.N.; Mazzotta, A.; La Torre, G.; De Giusti, M. Biological Risk and Occupational Health. Ind. Health 2012, 50, $326-337$. [CrossRef]

27. Collivignarelli, M.C.; Abbà, A.; Benigna, I.; Sorlini, S.; Torretta, V. Overview of the Main Disinfection Processes for Wastewater and Drinking Water Treatment Plants. Sustainability 2018, 10, 86. [CrossRef]

28. Crini, G.; Lichtfouse, E. Advantages and disadvantages of techniques used for wastewater treatment. Environ. Chem. Lett. 2019, 17, 145-155. [CrossRef]

29. Tušer, I.; Hoskova-Mayerova, S. Emergency Management in Resolving an Emergency Situation. J. Risk Financ. Manag. 2020, 13, 262. [CrossRef]

30. ISO 31000:2018 Risk Management-Guidelines, 2nd ed.; International Organization for Standardization: Geneva, Switzerland, 2018.

31. Łój-Pilch, M.; Zakrzewska, A. Analysis of Risk Assessment in a Municipal Wastewater Treatment Plant Located in Upper Silesia. Water 2020, 12, 23. [CrossRef]

32. Le Coze, J.-C. Are organisations too complex to be integrated in technical risk assessment and current safety auditing? Saf. Sci. 2005, 43, 613-638. [CrossRef]

33. Avci, O.; Ozbulut, O. Threat and vulnerability risk assessment for existing subway stations: A simplified approach. Case Stud. Transp. Policy 2018, 6, 663-673. [CrossRef]

34. Rausand, M. Risk Assessment: Theory, Methods, and Applications, 1st ed.; John Wiley: Hoboken, NJ, USA, 2011; p. 644. ISBN 978-0-470-63764-7.

35. Pritchard, C.L. Risk Management: Concepts and Guidance, 5th ed.; Taylor and Francis Group: New York, NY, USA, $2015 ;$ p. 442. ISBN 978-1-4822-5845-5. 
36. Vasilescu, G.D.; Petrilean, C.D.; Kovacs, A.; Vasilescu, G.V.; Pasculescu, D.; Ilcea, G.I.; Burduhos-Nergis, D.-P.; Bejinariu, C. Methodology for Assessing the Degree of Occupational Safety Specific to Hydrotechnical Construction Activities, in Order to Increase Their Sustainability. Sustainability 2021, 13, 1105. [CrossRef]

37. Crawley, F. Safety audits. In A Guide to Hazard Identification Methods; Elsevier: Amsterdam, The Netherlands, 2020 ; pp. 181-192. [CrossRef]

38. Allford, L. The auditing of process safety. J. Loss Prev. Process Ind. 2016, 43, 747-752. [CrossRef]

39. IEC 31010:2019 Risk Management_Risk Assessment Techniques: Standardization Documentation, 2nd ed.; International Organization for Standardization: Geneva, Switzerland, 2019.

40. Lewis, S.; Smith, K. Lessons Learned from Real World Application of the Bow-Tie Method. In Proceedings of the American Institute of Chemical Engineers 2010 Spring Meeting 6th Global Congress on Process Safety, San Antonio, TX, USA, 22-24 March 2010. Available online: https:/ / www.risktec.tuv.com/wp-content/uploads/2018/10/bow-tie-lessons-learned-aiche.pdf (accessed on 25 March 2021.).

41. Zhu, Q.; Kuang, X.; Shen, Y. Risk Matrix Method and Its Application in the Field of Technical Project Risk Management. Strateg. Study Chin. Acad. Eng. 2003, 5, 89-94.

42. ISO 73:2009 Risk Management_Vocabulary, 1st ed.; International Organization for Standardization: Geneva, Switzerland, 2009.

43. Hlavizna, P.; Oulehlova, A. Selected risk treatment of electronic warfare development. In Proceedings of the 30th European Safety and Reliability Conference, the 15th Probabilistic Safety Assessment and Management Conference, Venice, Italy, 1-5 November 2020; Research Publishing: Singapore, 2020; pp. 4302-4309.

44. Łój-Pilch, M.; Zakrzewska, A.; Zielewicz, E. Risk Assessment Analysis in a Municipal Wastewater Treatment Plant. Proceedings 2019, 16, 18. [CrossRef] 